\title{
Decreased Myocardial $\beta$-Adrenergic Receptor Density in Relation to Increased Sympathetic Tone in Patients with Nonischemic Cardiomyopathy
}

Takahiro Tsukamoto ${ }^{1}$, Koichi Morita ${ }^{2}$, Masanao Naya $^{1}$, Masayuki Inubushi ${ }^{2}$, Chietsugu $\mathrm{Katoh}^{2}$, Kenichi Nishijima ${ }^{3}$, Yuji Kuge ${ }^{2}$, Hiroshi Okamoto ${ }^{1}$, Hiroyuki Tsutsui ${ }^{1}$, and Nagara Tamaki ${ }^{2}$

${ }^{1}$ Department of Cardiovascular Medicine, Hokkaido University Graduate School of Medicine, Sapporo, Japan; ${ }^{2}$ Department of Nuclear Medicine, Hokkaido University Graduate School of Medicine, Sapporo, Japan; and ${ }^{3}$ Faculty of Radiopharmaceutical Science, Health Sciences University of Hokkaido, Sapporo, Japan

Cardiac sympathetic function plays an important role in the regulation of left ventricular (LV) function and the pathophysiology of LV dysfunction. ${ }^{11} \mathrm{C}$-CGP-12177 ( $\left.{ }^{11} \mathrm{C}-\mathrm{CGP}\right)$ has been used to assess myocardial $\beta$-adrenergic receptor ( $\beta-A R)$ density in vivo using PET. The aim of this study is to measure myocardial $\beta-A R$ density in patients with nonischemic cardiomyopathy and to compare the measurements with various standard parameters of heart failure (HF), particularly with presynaptic function assessed by ${ }^{123}$ I- metaiodobenzylguanidine (123I-MIBG) imaging. Methods: ${ }^{11} \mathrm{C}$-CGP PET was performed on 16 patients with nonischemic cardiomyopathy and 8 age-matched healthy volunteers using a double injection method. A ${ }^{11} \mathrm{C}-\mathrm{CGP}$ dynamic scan for 75 min was performed after the injection of ${ }^{11} \mathrm{C}-\mathrm{CGP}$ with a high specific activity. After $30 \mathrm{~min},{ }^{11} \mathrm{C}$-CGP with a low specific activity was injected. The $\beta$-AR density of the whole LV was calculated on the basis of the graphical analysis method. Additionally, $\beta$-AR density was compared with LV ejection fraction (LVEF), sympathetic presynaptic function assessed using 123I-MIBG kinetics, and neurohormonal parameters. Results: The $\beta$-AR density of patients was significantly lower than that of healthy volunteers $(3.80 \pm 0.96$ vs. $7.70 \pm 1.92 \mathrm{pmol} / \mathrm{mL}$; $P<0.0001)$. In the patients, $\beta$-AR density correlated significantly with LVEF $(r=0.62, P<0.05)$. Furthermore, $\beta$-AR density correlated significantly with the ${ }^{123}$ I-MIBG washout rate $(r=-0.68$, $P<0.01)$ and delayed heart-to-mediastinum ratio (H/M ratio) $(r=0.61, P<0.05)$. On the other hand, the correlation between $\beta$-AR density and early $\mathrm{H} / \mathrm{M}$ ratio was not significant $(r=0.40$, $P=0.13$ ). The $\beta$-AR density of patients with severe HF (New York Heart Association functional [NYHA] class III) was significantly lower than that of those with NYHA functional class I or class II HF (3.24 \pm 0.96 vs. $4.24 \pm 0.73 \mathrm{pmol} / \mathrm{mL} ; P<0.05)$. Conclusion: $A$ reduction in $\beta-A R$ density measured by ${ }^{11} \mathrm{C}$-CGP PET was observed in patients with nonischemic cardio-

Received May 30, 2007; revision accepted Aug. 18, 2007.

For correspondence or reprints contact: Nagara Tamaki, MD, Department of Nuclear Medicine, Graduate School of Medicine, Hokkaido University, Kita15 Nishi7, Kita-ku, Sapporo 060-8638, Japan.

E-mail: natamaki@med.hokudai.ac.jp

COPYRIGHT $\odot 2007$ by the Society of Nuclear Medicine, Inc. myopathy. This downregulation may be due to the increased presynaptic sympathetic tone as assessed by ${ }^{123}$ I-MIBG imaging.

Key Words: $\beta$-adrenergic receptor; heart failure; sympathetic tone; norepinephrine

J Nucl Med 2007; 48:1777-1782

DOI: 10.2967/jnumed.107.043794

$\mathbf{H}$

eart failure (HF) is a major cause of mortality and represents a growing health problem, despite major therapeutic advances (1-3). The severity of HF is evaluated primarily by symptoms, clinical findings, hemodynamic measurements, left ventricular ejection fraction (LVEF), or exercise tolerance (4-7). In addition, the assessment of neurohormonal system disorders related to $\mathrm{HF}$ has proven to be valuable for risk stratification (8-11). Despite these indices, the accurate evaluation of the risk of mortality remains difficult.

Cardiac sympathetic function plays an important role in the regulation of heart function and has been studied extensively in recent decades $(12,13)$. In a failing heart, the myocardial responsiveness to $\beta$-agonist stimulation is suppressed, primarily because of the downregulation of $\beta 1$-adrenergic receptor (AR) $(14,15)$. This $\beta$-AR downregulation has been induced by an enhanced sympathetic activity to the heart and an enhanced release of endogenous cardiac-derived catecholamines (16). The degree of downregulation is related to the severity of HF (15). Furthermore, these patients have higher levels of circulating catecholamines, which are inversely related to prognosis (8). On the basis of these findings, a beneficial effect of $\beta$-adrenergic blocker therapy has been hypothesized. In fact, many trials have shown the beneficial effect of $\beta$-blocker therapy in heart failure patients (3).

However, this in vitro measurement is invasive and does not allow longitudinal and regional assessment in humans. PET is an excellent noninvasive tool for investigating the distribution of myocardial $\beta-A R$ in vivo and provides the 
possibility of repeated measurements. Studies using PET and the radioligand ${ }^{11} \mathrm{C}$-CGP-12177 $\left({ }^{11} \mathrm{C}\right.$-CGP) have shown promising results that are in agreement with those of in vitro studies (17). CGP appears to be the most suitable ligand because it is very potent and is a hydrophilic nonselective $\beta$-AR antagonist with low nonspecific binding on membranes and slight cellular uptake (18). CGP enables the investigation of plasma membrane receptors. However, CGP has not been studied extensively in vivo because of difficulty in the synthesis of ${ }^{11} \mathrm{C}$-CGP. We developed a method for producing ${ }^{11} \mathrm{C}$-CGP with very high yield and specific activity, which provides high-quality images and the clinical application for myocardial $\beta$-AR density $(19,20)$.

Merlet et al. demonstrated the downregulation of $\beta$-AR in patients with HF caused by idiopathic dilated cardiomyopathy (17). We hypothesized that this downregulation may be related to the adrenergic presynaptic dysfunction. However, there is little information about the relationship between presynaptic function and $\beta$-AR density in HF. The aim of this study was to measure myocardial $\beta$-AR density in patients with nonischemic left ventricular (LV) dysfunction using ${ }^{11} \mathrm{C}$-CGP PET and to compare the measured values with various standard parameters of $\mathrm{HF}$ and presynaptic function. Adrenergic presynaptic function was assessed by ${ }^{123}$ I-metaiodobenzylguanidine ( $\left.{ }^{123} \mathrm{I}-\mathrm{MIBG}\right)$ imaging. ${ }^{123} \mathrm{I}-$ MIBG, a norepinephrine (NE) analog, is accumulated in sympathetic nerve endings through the uptake-1 mechanism and can be used to delineate cardiac sympathetic nerve distribution and function (21-23).

\section{MATERIALS AND METHODS}

\section{Study Patients}

In this study, we enrolled 16 patients diagnosed as having nonischemic cardiomyopathy ( 8 men, 8 women; mean age $\pm \mathrm{SD}$, $62.8 \pm 11.1 \mathrm{y}$ ). All patients had LV dysfunction (LVEF $<45 \%$ ) but showed normal coronary angiography. All patients underwent ${ }^{11} \mathrm{C}$-CGP PET and ${ }^{123}$ I-MIBG imaging within 1 mo (mean time, $15 \mathrm{~d}$ ) during the stable stage of HF. No clinical events or changes in medication occurred during these 2 studies. Because treatment with a $\beta$-blocker is known to affect myocardial $\beta$-AR density, patients with a history of $\beta$-blocker treatment were excluded from the study.

\section{Control Subjects}

Eight age-matched healthy volunteers ( 6 men, 2 women; mean age $\pm \mathrm{SD}, 57.6 \pm 13.0 \mathrm{y} ; P=$ not significant vs. patients) served as control subjects for the measurements of $\beta$-AR density. They showed no sign of cardiac disease and each had a normal resting electrocardiogram. This study was approved by the Ethics Committee of Hokkaido University Hospital. All subjects gave their written informed consent for the study.

\section{PET Data Acquisition}

All PET scans were obtained using an ECAT EXACT HR+ (Siemens Medical Solutions, Inc.). A transmission scan was performed to correct photon attenuation for $8 \mathrm{~min}$ with a ${ }^{68} \mathrm{Ge}$ source. ${ }^{11} \mathrm{C}$-CGP was prepared as reported previously $(21,22)$. The measurement of myocardial $\beta$-AR density using ${ }^{11} \mathrm{C}$-CGP PET was performed according to a modified double-injection protocol reported previously (24,25). During a 75-min dynamic emission scan, the first dose of ${ }^{11} \mathrm{C}-\mathrm{CGP}$ with a high specific activity $(169 \pm 65 \mathrm{MBq}, 0.19 \pm 0.13 \mu \mathrm{g})$ was infused intravenously over a 2-min period. Thirty minutes later, the second dose of ${ }^{11} \mathrm{C}$-CGP with a low specific activity $(312 \pm 145 \mathrm{MBq}, 22.0 \pm 1.8 \mu \mathrm{g})$ was again infused over a 2-min period. A 54-frame dynamic emission scan was used for measurement of the sequential distributions of the tracer in vivo. During the 30-min period after the start of the first infusion, 24 time frames $(8 \times 15-\mathrm{s}, 4 \times 30$-s, $2 \times 60$-s, $2 \times$ 120 -s, and $8 \times 150$-s frames) were acquired. After the second infusion, the scan was completed with 30 frames $(8 \times 15$-s, $4 \times$ 30 -s, $2 \times 60$-s, $2 \times 120$-s, and $14 \times 150$-s frames).

\section{PET Data Analysis}

All emission sinograms were reconstructed with filtered backprojection using a Hann filter (cutoff frequency, 0.3 cycle/pixel). The in-plane resolution was $4.5-\mathrm{mm}$ full width at half maximum in the images reconstructed into a $128 \times 128$ matrix. All data were corrected for dead time, decay, and measured photon attenuation. A whole-heart region of interest (ROI) was set manually in each transaxial view. Myocardial time-activity curves in the ROIs were corrected for radioactive decay and for vascular activity using the regional values of blood volume. The sections of the curve corresponding to the 2 slow clearance phases, which represent the dissociation of ${ }^{11} \mathrm{C}-\mathrm{CGP}$ bound to $\beta$-AR, were extrapolated back to the start of the infusions. $\beta$-AR density was then determined as the maximum number of available specific ${ }^{11} \mathrm{C}$-CGPbinding sites per gram of tissue $\left(\mathrm{B}_{\max }\right)$ in the ROIs using a modified equation described by Delforge et al. $(24,25)$.

\section{3/-MIBG Data Acquisition and Analysis}

${ }^{123}$ I-MIBG (111 MBq) (Dai-ichi Radioisotope Laboratories, LTD.) was injected intravenously into the patients under resting and fasting conditions. Fifteen minutes and $4 \mathrm{~h}$ after the injection, static planar images were acquired in the anterior view using a dual-head $\gamma$-camera (ADAC Vertex Plus; Phillips) equipped with low-energy, general-purpose collimators. Static images on $512 \times$ 512 matrices were collected for $5 \mathrm{~min}$ with a $20 \%$ window centered at $159 \mathrm{keV}$. Subsequently, SPECT of the heart was performed in $64 \times 64$ matrices using a filtered backprojection method for reconstruction. A ramp filter and a Butterworth filter with an order of 5.0 and a cutoff frequency of 0.50 cycle per pixel were used for reconstruction. No attenuation or scatter correction was performed. LV uptake was assessed by quantitative analysis performed manually drawing the ROI over the LV in the anterior view. The rectangular ROIs of $9 \times 9$ pixels were placed over the upper mediastinum. Counts per pixel were calculated from each ROI located in the heart and the mediastinum. The heart-tomediastinum count ratios (H/M ratios) of early and delayed planar images were computed to quantify the cardiac uptake of ${ }^{123} \mathrm{I}-$ MIBG. The washout rate (WR) was calculated using the following formula:

$$
\mathrm{WR}(\%)=(\mathrm{H} \text { at } 15 \mathrm{~min}-\mathrm{H} \text { at } 4 \mathrm{~h}) /(\mathrm{H} \text { at } 15 \mathrm{~min} \times 100),
$$

where $\mathrm{H}=$ mean counts per pixel in the $\mathrm{LV}$.

\section{Echocardiography}

Echocardiography was performed in all patients at about the same time as ${ }^{11} \mathrm{C}$-CGP PET. LVEF was measured from apical 2-chamber 
and 4-chamber images using the biplane disk-summation method based on the standards of the American Society of Echocardiography (26).

\section{Measurement of Neurohormonal Parameters}

Before the PET study was started, venous blood samples were drawn after a 20-min resting period in the supine position. Plasma $\mathrm{NE}$ levels were measured using high-performance liquid chromatography. Plasma brain natriuretic peptide (BNP) levels were measured by chemiluminescent enzyme immunoassay.

\section{Statistical Analysis}

All data were expressed as mean \pm SD. Regression analysis was performed using a linear regression method. A Student $t$ test was performed to test differences between patients and control subjects. A $P$ value $<0.05$ was considered statistically significant. In addition, multivariate stepwise regression analyses were performed to investigate whether the $\beta$-AR density was associated independently with LVEF or NYHA class or whether it was dependent on presynaptic changes of plasma neurohumoral levels.

\section{RESULTS}

${ }^{11} \mathrm{C}$-CGP was produced with a very high yield $(1,964 \pm$ $1,105 \mathrm{MBq})$ and specific activity $(485 \pm 370 \mathrm{GBq} / \mu \mathrm{mol})$. The characteristics of the patients are shown in Table 1 . Four patients were classified as New York Heart Association (NYHA) functional class I, 5 patients as class II, and 7 patients as class III at the time of the PET scan. Although the BNP levels of the patients were significantly higher than those of the control subjects $(183 \pm 143$ vs. $26 \pm 24$ $\mathrm{pg} / \mathrm{mL} ; P<0.05)$, there was no significant difference in the NE levels between the 2 groups ( $367 \pm 235$ vs. $249 \pm 116$ $\mathrm{pg} / \mathrm{mL} ; P=0.20$ ).

The calculated $\beta$-AR densities are shown in Figure 1. The $\beta$-AR density of the patients was significantly reduced by $51 \%$ in comparison with that of the control subjects $(3.80 \pm 0.96$ vs. $7.70 \pm 1.92 \mathrm{pmol} / \mathrm{mL} ; P<0.0001)$. In the

TABLE 1

Clinical Characteristics of 16 Patients

\begin{tabular}{lc}
\hline \multicolumn{1}{c}{ Characteristic } & Value \\
\hline Age $(\mathrm{y})$ & $62.8 \pm 11.1$ \\
Sex (M/F) & $8 / 8$ \\
LVEF (\%) & $31.0 \pm 10.1$ \\
BNP level $(\mathrm{pg} / \mathrm{mL})$ & $183 \pm 143$ \\
NE level $(\mathrm{pg} / \mathrm{mL})$ & $367 \pm 235$ \\
NYHA class* & \\
I & $4(25)$ \\
II & $5(31)$ \\
III & $7(44)$ \\
Medication* & \\
ACEI or ARB & $14(88)$ \\
Diuretics & $12(75)$ \\
Spironolactone & $7(44)$ \\
Digitalis & $5(31)$ \\
& \\
*Values are expressed as no. (\%). & \\
NYHA = New York Heart Association; ACEl & $=$ angiotensin- \\
converting enzyme inhibitor; ARB = angiotensin II receptor blocker.
\end{tabular}

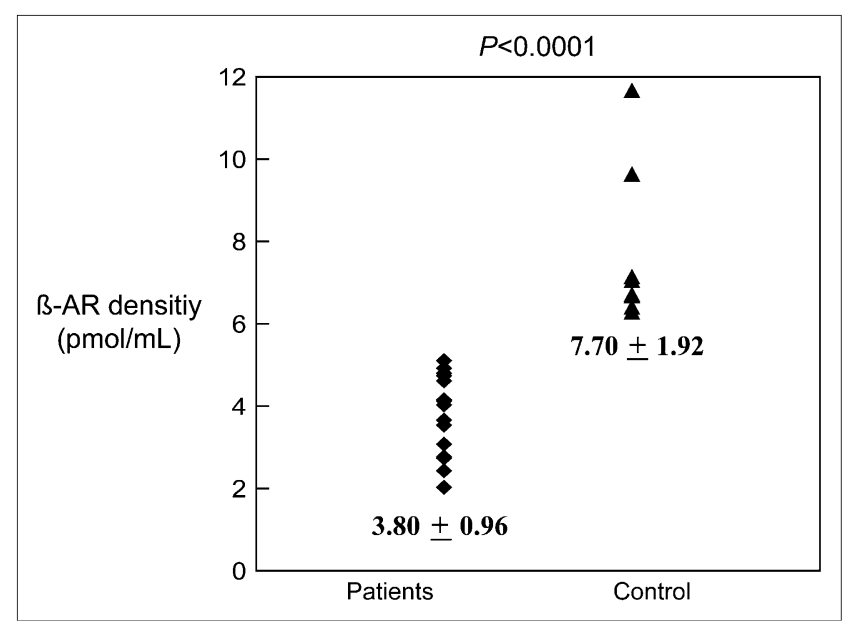

FIGURE 1. Comparison of $\beta-A R$ density between patients with HF and control subjects.

patients, $\beta$-AR density correlated significantly with LVEF $(r=0.62, P<0.05$; Fig. 2$)$. Furthermore, $\beta$-AR density showed good correlations with ${ }^{123}$ I-MIBG WR $(r=-0.68$, $P<0.01$; Fig. 3A) and delayed $\mathrm{H} / \mathrm{M}$ ratio $(r=0.61, P<$ 0.05 ; Fig. 3B). The correlation between $\beta$-AR density and early $\mathrm{H} / \mathrm{M}$ ratio was not significant $(r=0.40, P=0.13$; Fig. 3C). $\beta$-AR density showed no correlation with BNP levels $(r=-0.26, P=0.33)$ or NE levels $(r=-0.44, P=0.09)$.

$\beta$-AR density of the patients with severe HF (NYHA class III) was significantly lower than that of those with mild HF (NYHA class I or II) $(3.24 \pm 0.96$ vs. $4.24 \pm 0.73$ $\mathrm{pmol} / \mathrm{mL}, P<0.05$; Table 2 ). There were no significant differences in early $\mathrm{H} / \mathrm{M}$ ratios $(1.76 \pm 0.41$ vs. $2.01 \pm$ $0.35 ; P=0.22)$ and delayed $\mathrm{H} / \mathrm{M}$ ratios $(1.49 \pm 0.40 \mathrm{vs}$. $1.88 \pm 0.38 ; P=0.07)$, WR $(41.4 \% \pm 6.1 \%$ vs. $37.2 \% \pm$ $7.7 \% ; P=0.26)$, and BNP levels $(201 \pm 129$ vs. $169 \pm$ $159 \mathrm{pg} / \mathrm{mL} ; P=0.66$ ) between these 2 groups. The LVEF $(24.6 \% \pm 11.0 \%$ vs. $36.0 \% \pm 5.9 \% ; P<0.05)$ and NE levels (584 \pm 188 vs. $198 \pm 60 \mathrm{pg} / \mathrm{mL} ; P<0.0001)$ of the severe HF group were significantly lower than those of the mild HF group (Table 2).

$\beta$-AR density significantly correlated with NYHA class $(r=-0.61, P<0.05), \mathrm{LVEF},{ }^{123} \mathrm{I}-\mathrm{MIBG} \mathrm{WR}$, and delayed

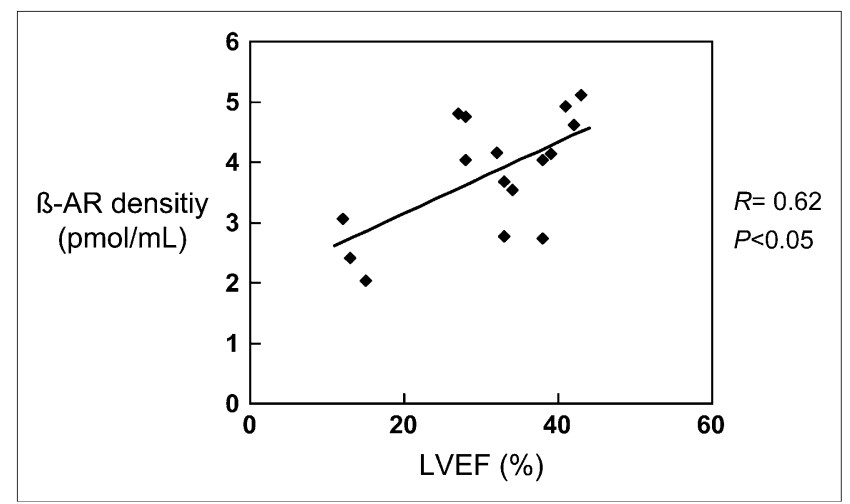

FIGURE 2. Relationship between LVEF and $\beta-A R$ density. 


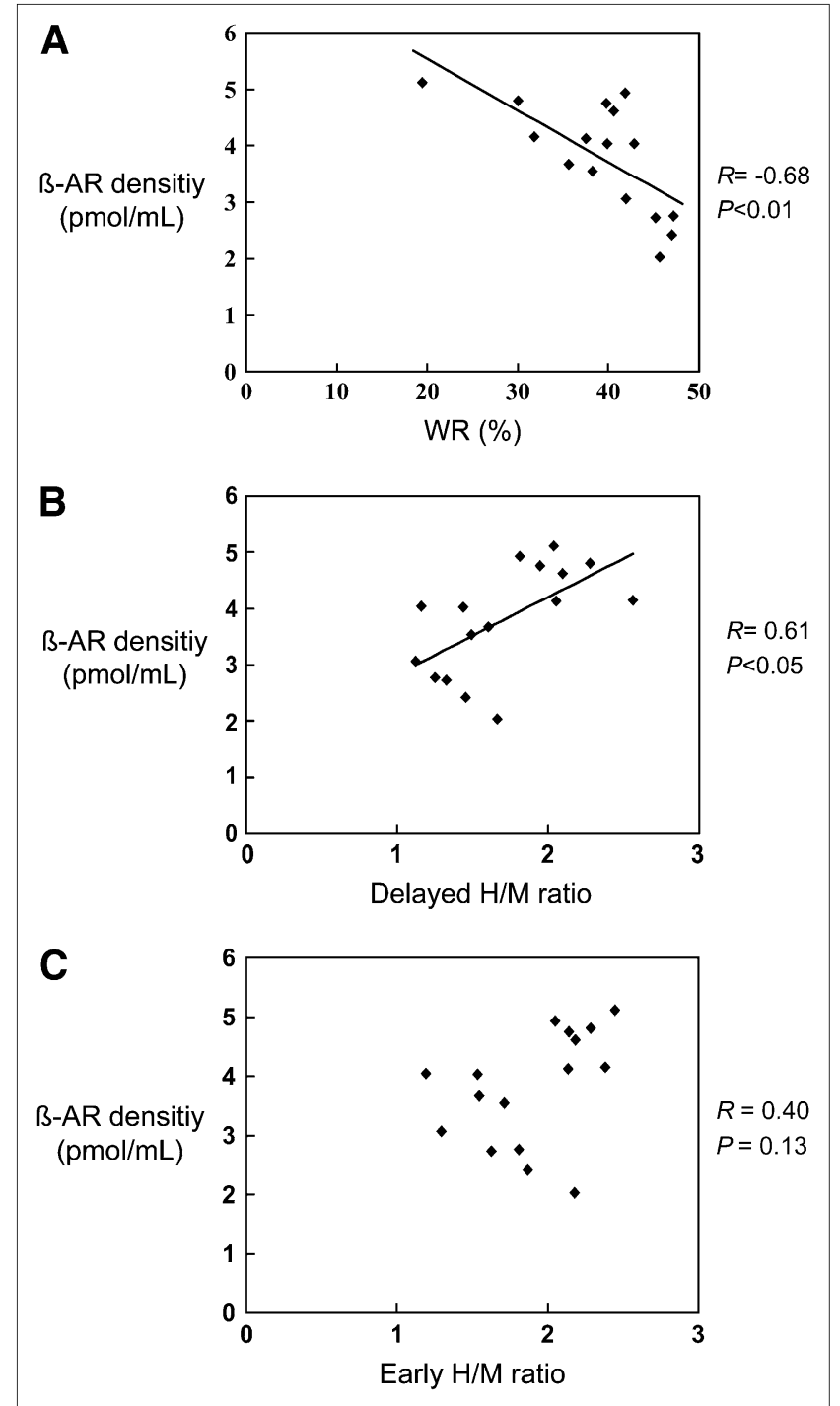

FIGURE 3. (A) Relationship between ${ }^{123}$ I-MIBG WR and $\beta-A R$ density. (B) Relationship between delayed ${ }^{123}$ I-MIBG H/M ratio and $\beta$-AR density. (C) Relationship between early ${ }^{123}$ I-MIBG $\mathrm{H} / \mathrm{M}$ ratio and $\beta-A R$ density.

$\mathrm{H} / \mathrm{M}$ ratio. In multivariate analysis, delayed $\mathrm{H} / \mathrm{M}$ ratio was excluded, because there was a significant correlation between ${ }^{123} \mathrm{I}$-MIBG WR and delayed H/M ratio $(r=-0.62$, $P<0.05)$. ${ }^{123}$ I-MIBG WR $(r=-0.70)$ and NYHA class $(r=-0.50)$ were the determinants of myocardial $\beta$-AR density by multivariate stepwise analysis. By multivariate stepwise analysis, $\beta$-AR density was the only significant determinant of LVEF $(r=0.58)$ among $\beta$-AR density, ${ }^{123} \mathrm{I}-$ MIBG WR, BNP level, and NE level. In contrast, NE level was the only determinant of NYHA class $(r=0.73)$.

\section{DISCUSSION}

This study showed that the myocardial $\beta$-AR density of the patients with nonischemic cardiomyopathy was significantly reduced by $51 \%$ in comparison with that of the age-matched control subjects. Myocardial $\beta$-AR density showed good
TABLE 2

NYHA Classification and Parameters of HF

\begin{tabular}{|c|c|c|c|}
\hline Parameter & $\begin{array}{c}\text { Mild HF } \\
(n=9): \\
\text { NYHA } \\
\text { class I or II }\end{array}$ & $\begin{array}{c}\text { Severe HF } \\
(n=7): \\
\text { NYHA } \\
\text { class III }\end{array}$ & $P$ value \\
\hline$\beta$-AR density (pmol/mL) & $4.24 \pm 0.73$ & $3.24 \pm 0.96$ & $<0.05$ \\
\hline Early $\mathrm{H} / \mathrm{M}$ ratio & $2.01 \pm 0.35$ & $1.76 \pm 0.41$ & 0.22 \\
\hline Delayed $\mathrm{H} / \mathrm{M}$ ratio & $1.88 \pm 0.38$ & $1.49 \pm 0.40$ & 0.07 \\
\hline 123I-MIBG WR (\%) & $37.2 \pm 7.7$ & $41.4 \pm 6.1$ & 0.26 \\
\hline LVEF (\%) & $36.0 \pm 5.9$ & $24.6 \pm 11.0$ & $<0.05$ \\
\hline BNP level (pg/mL) & $169 \pm 159$ & $201 \pm 129$ & 0.66 \\
\hline NE level (pg/mL) & $198 \pm 60$ & $584 \pm 188$ & $<0.0001$ \\
\hline
\end{tabular}

correlations with LVEF, ${ }^{123}$ I-MIBG WR, and delayed H/M ratio but not with plasma BNP level or NE level.

$\beta$-AR density was reduced with decreasing LVEF. Severe HF patients showed a greater reduction in $\beta$-AR density than mild HF patients, indicating that a decrease in $\beta$-AR density reflects the severity of HF. On the other hand, $\beta$-AR density showed no correlation with plasma BNP level or NE level. These neurohormonal levels may change rapidly depending on the condition of HF. Because this study was performed at the stable stage of HF, these neurohormonal levels might have already returned to near-normal levels. In contrast, it is not clear whether $\beta$-AR density may change so rapidly. Therefore, such chronological differences might possibly cause little or no significant correlation between $\beta$-AR density and these neurohormonal parameters.

Bristow et al. showed a reduction in $\beta$-AR density in a failing human heart using an in vitro ligand-binding technique (14). They reported 50\%-56\% reductions in $\beta$-AR density. In 1993 Merlet et al. reported in vivo measurements of $\beta$-AR density using PET and ${ }^{11} \mathrm{C}$-CGP (17). They showed downregulation of $\beta$-AR by $53 \%$ with correlation with LVEF in the patients with idiopathic dilated cardiomyopathy. Our current results are in agreement with these previous reports.

Increased presynaptic activity in the failing human heart $(8,16)$ and a decrease of postsynaptic $\beta$-AR density in failing heart $(14,15,17)$ have been reported. In our study, the degree of $\beta$-AR downregulation corresponded to the increase in ${ }^{123}$ I-MIBG WR and a decrease in delayed H/M ratio. Because MIBG is a NE analog, WR and delayed $\mathrm{H} / \mathrm{M}$ ratio may directly reflect $\mathrm{NE}$ release from the nerve terminal and its reuptake into the nerve terminal (uptake-1). In addition, the ${ }^{123}$ I-MIBG WR may reflect presynaptic sympathetic tone. The local NE concentration in the synaptic cleft increases when WR increases or delayed H/M ratio decreases (21-23). Our results may confirm the hypothesis that the increase in NE concentration in the synaptic cleft contributes to myocardial $\beta$-AR downregulation (27-29). Furthermore, the present study confirms pathophysiologic conditions of failing heart, which have been proven clinically over decades. 
On the other hand, the correlation between $\beta$-AR density and early $\mathrm{H} / \mathrm{M}$ ratio was not significant. It has been reported that an early MIBG uptake reflects only the integrity of presynaptic nerve terminals and their uptake-1 function, whereas a delayed MIBG uptake represents overall information with regard to neural function at the nerve terminal (30).

Schafers et al. reported $\beta$-AR downregulation and an impaired uptake-1 mechanism in patients with hypertrophic cardiomyopathy using ${ }^{11} \mathrm{C}-\mathrm{CGP}$ and ${ }^{11} \mathrm{C}$-hydroxyephedrin $\left({ }^{11} \mathrm{C}-\mathrm{HED}\right)$ PET (28). In their study, all patients had preserved LV systolic function and no evidence of HF. To our knowledge, there is no information with regard to the relationship between presynaptic and postsynaptic functions in HF in vivo. Our results show a precise correlation between $\beta$-AR density estimated by ${ }^{11} \mathrm{C}-\mathrm{CGP}$ PET and presynaptic function determined by ${ }^{123}$ I-MIBG imaging in HF patients.

${ }^{123}$ I-MIBG imaging has been widely used for the assessment of cardiac sympathetic function in HF $(22,23,31-34)$. In many studies, it has been reported that impaired cardiac adrenergic innervation as assessed by ${ }^{123}$ I-MIBG imaging was closely associated with mortality in patients with HF (35-37). Some studies demonstrated that ${ }^{123}$ I-MIBG imaging was a good predictor of response to adrenergic $\beta$-blocker therapy $(38,39)$. Spyrou et al. reported that $\beta$-AR downregulation can be used as a predictor of $L V$ remodeling in patients after acute myocardial infarction (40). Further studies may be needed to evaluate the relationship between $\beta$-AR density, prognosis, and response to therapy in a larger patient population.

As a first limitation of this study, we used different methods for assessment of presynaptic and postsynaptic function. ${ }^{11} \mathrm{C}$ HED enables quantitative assessment of presynaptic function using PET. Because presynaptic function was assessed using ${ }^{123}$ I-MIBG imaging instead of ${ }^{11} \mathrm{C}-\mathrm{HED}$, an accurate quantification of presynaptic function might be limited. The resolution of ${ }^{123}$ I-MIBG imaging is inferior to PET. Attenuation and scatter correction were not performed in this study. Myocardial ${ }^{123}$ I-MIBG imaging was analyzed semiquantitatively by using the $\mathrm{H} / \mathrm{M}$ ratio on early and delayed planar images and the myocardial WR. However, we do not believe that attenuation and scatter may affect these parameters, because these parameters were relative values calculated from the counts in the anterior planar images. On the other hand, MIBG has advantages for estimating the integrity of presynaptic nerve terminals, their uptake- 1 function, and sympathetic tone. Although we applied commonly used parameters from MIBG imaging, a better quantitative measurement may be needed for further analysis.

Because the number of patients in this study was small $(n=16)$ and the follow-up time was limited, cardiac events were not observed in the patients. Thus, we did not evaluate the prognostic value of $\beta$-AR density in this study. However, because this parameter was correlated with LVEF, NYHA, and MIBG parameters, $\beta$-AR may have the poten- tial for risk stratification in patients with HF. Further study is warranted to confirm the prognostic value.

\section{CONCLUSION}

Decreased cardiac $\beta$-AR density measured by ${ }^{11} \mathrm{C}-\mathrm{CGP}$ PET was observed in patients with nonischemic cardiomyopathy. In addition, $\beta$-AR density correlated with ${ }^{123} \mathrm{I}-\mathrm{MIBG}$ WR and delayed H/M ratio. This downregulation may be due to an accelerated presynaptic sympathetic tone.

\section{REFERENCES}

1. Studies of left ventricular dysfunction (SOLVD): rationale, design and methodstwo trials that evaluate the effect of enalapril in patients with reduced ejection fraction. Am J Cardiol. 1990;66:315-322.

2. Pfeffer MA, Braunwald E, Moye LA, et al. Effect of captopril on mortality and morbidity in patients with left ventricular dysfunction after myocardial infarction: results of the survival and ventricular enlargement trial- the SAVE Investigators. N Engl J Med. 1992;327:669-677.

3. Packer M, Bristow MR, Cohn JN, et al. The effect of carvedilol on morbidity and mortality in patients with chronic heart failure: U.S. Carvedilol Heart Failure Study Group. N Engl J Med. 1996;334:1349-1355.

4. Schwarz F, Mall G, Zebe H, et al. Determinants of survival in patients with congestive cardiomyopathy: quantitative morphologic findings and left ventricular hemodynamics. Circulation. 1984;70:923-928.

5. Corbett JR, Dehmer GJ, Lewis SE, et al. The prognostic value of submaximal exercise testing with radionuclide ventriculography before hospital discharge in patients with recent myocardial infarction. Circulation. 1981;64:535-544.

6. Cintron G, Johnson G, Francis G, Cobb F, Cohn JN. Prognostic significance of serial changes in left ventricular ejection fraction in patients with congestive heart failure: the V-HeFT VA Cooperative Studies Group. Circulation. 1993; 87(suppl):VI17-VI23.

7. Mancini DM, Eisen H, Kussmaul W, Mull R, Edmunds LH Jr, Wilson JR. Value of peak exercise oxygen consumption for optimal timing of cardiac transplantation in ambulatory patients with heart failure. Circulation. 1991;83:778-786.

8. Cohn JN, Levine TB, Olivari MT, et al. Plasma norepinephrine as a guide to prognosis in patients with chronic congestive heart failure. N Engl J Med. 1984; 311:819-823.

9. Hall C, Rouleau JL, Moye L, et al. N-terminal proatrial natriuretic factor: an independent predictor of long-term prognosis after myocardial infarction. Circulation. 1994;89:1934-1942.

10. Omland T, Aakvaag A, Bonarjee VV, et al. Plasma brain natriuretic peptide as an indicator of left ventricular systolic function and long-term survival after acute myocardial infarction: comparison with plasma atrial natriuretic peptide and N-terminal proatrial natriuretic peptide. Circulation. 1996;93:1963-1969.

11. Tsutamoto T, Wada A, Maeda K, et al. Attenuation of compensation of endogenous cardiac natriuretic peptide system in chronic heart failure: prognostic role of plasma brain natriuretic peptide concentration in patients with chronic symptomatic left ventricular dysfunction. Circulation. 1997;96:509-516.

12. Bristow MR, Hershberger RE, Port JD, et al. Beta-adrenergic pathways in nonfailing and failing human ventricular myocardium. Circulation. 1990;82(suppl): I12-I25.

13. Port JD, Bristow MR. Altered beta-adrenergic receptor gene regulation and signaling in chronic heart failure. J Mol Cell Cardiol. 2001;33:887-905.

14. Bristow MR, Ginsburg R, Minobe W, et al. Decreased catecholamine sensitivity and beta-adrenergic-receptor density in failing human hearts. N Engl J Med. 1982; 307:205-211.

15. Fowler MB, Laser JA, Hopkins GL, Minobe W, Bristow MR. Assessment of the beta-adrenergic receptor pathway in the intact failing human heart: progressive receptor down-regulation and subsensitivity to agonist response. Circulation. 1986; 74:1290-1302.

16. Ruffolo RR Jr, Kopia GA. Importance of receptor regulation in the pathophysiology and therapy of congestive heart failure. Am J Med. 1986;80:67-72.

17. Merlet P, Delforge J, Syrota A, et al. Positron emission tomography with ${ }^{11} \mathrm{C}$ CGP-12177 to assess beta-adrenergic receptor concentration in idiopathic dilated cardiomyopathy. Circulation. 1993;87:1169-1178.

18. Staehelin M, Simons P, Jaeggi K, Wigger N. CGP-12177: a hydrophilic betaadrenergic receptor radioligand reveals high affinity binding of agonists to intact cells. J Biol Chem. 1983;258:3496-3502. 
19. Nishijima K, Kuge Y, Seki K, et al. A simplified and improved synthesis of $\left[{ }^{11}\right.$ C]phosgene with iron and iron (III) oxide. Nucl Med Biol. 2002;29:345-350.

20. Nishijima K, Kuge Y, Seki K, et al. Preparation and pharmaceutical evaluation for clinical application of high specific activity S-(-) $\left[{ }^{11} \mathrm{C}\right] \mathrm{CGP}-12177$, a radioligand for beta-adrenoreceptors. Nucl Med Commun. 2004;25:845-849.

21. Wieland DM, Brown LE, Rogers WL, et al. Myocardial imaging with a radioiodinated norepinephrine storage analog. J Nucl Med. 1981;22:22-31.

22. Henderson EB, Kahn JK, Corbett JR, et al. Abnormal I-123 metaiodobenzylguanidine myocardial washout and distribution may reflect myocardial adrenergic derangement in patients with congestive cardiomyopathy. Circulation. 1988; 78:1192-1199.

23. Schofer J, Spielmann R, Schuchert A, Weber K, Schluter M. Iodine-123 metaiodobenzylguanidine scintigraphy: a noninvasive method to demonstrate myocardial adrenergic nervous system disintegrity in patients with idiopathic dilated cardiomyopathy. J Am Coll Cardiol. 1988;12:1252-1258.

24. Delforge J, Syrota A, Lancon JP, et al. Cardiac beta-adrenergic receptor density measured in vivo using PET, CGP 12177, and a new graphical method. J Nucl Med. 1991;32:739-748.

25. Delforge J, Mesangeau D, Dolle F, et al. In vivo quantification and parametric images of the cardiac beta-adrenergic receptor density. J Nucl Med. 2002;43: 215-226.

26. Schiller NB, Shah PM, Crawford M, et al. Recommendations for quantitation of the left ventricle by two-dimensional echocardiography: American Society of Echocardiography Committee on Standards, Subcommittee on Quantitation of Two-Dimensional Echocardiograms. J Am Soc Echocardiogr. 1989;2:358-367.

27. Bristow MR, Minobe W, Rasmussen R, et al. Beta-adrenergic neuroeffector abnormalities in the failing human heart are produced by local rather than systemic mechanisms. J Clin Invest. 1992;89:803-815.

28. Schafers M, Dutka D, Rhodes CG, et al. Myocardial presynaptic and postsynaptic autonomic dysfunction in hypertrophic cardiomyopathy. Circ Res. 1998;82:57-62.

29. Mardon K, Montagne O, Elbaz N, et al. Uptake-1 carrier downregulates in parallel with the beta-adrenergic receptor desensitization in rat hearts chronically exposed to high levels of circulating norepinephrine: implications for cardiac neuroimaging in human cardiomyopathies. J Nucl Med. 2003;44:1459-1466.
30. Sisson JC, Wieland DM, Sherman P, Mangner TJ, Tobes MC, Jacques S Jr. Metaiodobenzylguanidine as an index of the adrenergic nervous system integrity and function. J Nucl Med. 1987;28:1620-1624.

31. Glowniak JV, Turner FE, Gray LL, Palac RT, Lagunas-Solar MC, Woodward WR. Iodine-123 metaiodobenzylguanidine imaging of the heart in idiopathic congestive cardiomyopathy and cardiac transplants. J Nucl Med. 1989;30:11821191 .

32. Merlet P, Dubois-Rande JL, Adnot S, et al. Myocardial beta-adrenergic desensitization and neuronal norepinephrine uptake function in idiopathic dilated cardiomyopathy. J Cardiovasc Pharmacol. 1992;19:10-16.

33. Merlet P, Pouillart F, Dubois-Rande JL, et al. Sympathetic nerve alterations assessed with ${ }^{123}$ I-MIBG in the failing human heart. J Nucl Med. 1999;40:224231.

34. Cohen-Solal A, Rouzet F, Berdeaux A, et al. Effects of carvedilol on myocardial sympathetic innervation in patients with chronic heart failure. J Nucl Med. 2005; 46:1796-1803.

35. Merlet P, Valette H, Dubois-Rande JL, et al. Prognostic value of cardiac metaiodobenzylguanidine imaging in patients with heart failure. J Nucl Med. 1992; 33:471-477.

36. Merlet P, Benvenuti C, Moyse D, et al. Prognostic value of MIBG imaging in idiopathic dilated cardiomyopathy. J Nucl Med. 1999;40:917-923.

37. Momose M, Kobayashi H, Iguchi N, et al. Comparison of parameters of ${ }^{123} \mathrm{I}-$ MIBG scintigraphy for predicting prognosis in patients with dilated cardiomyopathy. Nucl Med Commun. 1999;20:529-535.

38. Suwa M, Otake Y, Moriguchi A, et al. Iodine-123 metaiodobenzylguanidine myocardial scintigraphy for prediction of response to beta-blocker therapy in patients with dilated cardiomyopathy. Am Heart J. 1997;133:353-358.

39. Kakuchi H, Sasaki T, Ishida Y, Komamura K, Miyatake K. Clinical usefulness of ${ }^{123}$ I meta-iodobenzylguanidine imaging in predicting the effectiveness of beta blockers for patients with idiopathic dilated cardiomyopathy before and soon after treatment. Heart. 1999;81:148-152.

40. Spyrou N, Rosen SD, Fath-Ordoubadi F, et al. Myocardial beta-adrenoceptor density one month after acute myocardial infarction predicts left ventricular volumes at six months. J Am Coll Cardiol. 2002;40:1216-1224. 